\title{
Health foods
}

\section{By A. E. BENDER, Department of Food Science and Nutrition, Queen Elizabeth College, London $W 8$}

There are approximately $75^{\circ}$ health food shops in Britain selling a range of foods, herbal remedies and other materials and about roo 'wholefood' shops selling a limited range of, mostly, unpackaged foods. The turnover is about $f_{4}$ om of which about two-thirds is spent on food.

There is little agreement between health food enthusiasts, some are vegetarians, some believe that it is impossible to obtain all the required nutrients without dietary supplements, but all maintain that most disorders are due to nutritional deficiencies and that there is little nutritional value in modern, intensively farmed and processed foods.

Consumers may be occasional purchasers of some products or wholehearted believers in the mysticism surrounding the whole subject, referring to it as a 'spiritual reawakening' and as a harmonious relationship between man and his environment.

Some people have found it difficult to define health foods because they have attempted to discuss a wide variety of food products, preparations, cosmetics, books and dietary régimes under a single heading. To embrace so wide a variety of subjects they may be classified as follows.

\section{Classification of health foods}

Vegetarianism. There is a popular tendency to ridicule vegetarianism and to believe that meat is necessary for 'strength'. While it is obvious that very large numbers of people are quite adequately fed on vegetarian diets there can be problems, such as provision of adequate quantity and quality of protein, the effects of a high intake of dietary fibre on minerals and, more particularly, the supply of vitamin $B_{12}$.

Nutritional problems that have been reported refer almost entirely to $B_{12}$. Severe $B_{12}$ deficiency has been reported in very few cases and the diagnosis of the two deaths from subacute combined degeneration of the spinal cord has been questioned (Sanders et al. 1978) although one case has been reported in a breastfed infant of a vegetarian mother (Higginbottom et al. 1978). Very few normal plant foods contain $B_{12}$ (seaweeds, root nodules from leguminous plants and certain yeasts) and it has been suggested that vegans may obtain their $B_{12}$ from accidental ingestion of insects (Sanders et al. 1978) or from contaminated food (Rose, 1976). Such few isolated cases are no commoner, however, than the four cases of histamine poisoning reported from mackerel, adding to the 1,700 recorded cases of poisoning from scromboid fish (Cruickshank \& Williams, 1978 ) which is 
not regarded as a reason to denigrate fish and chip addicts. On the other hand several hundred cases of $B_{12}$ deficiency have been reported among Asian immigrants to Britain (Rose, 1976).

Apart from this specific problem vegetarians and even vegans are no more nor less healthy than omnivores (Ellis \& Mumford, 1967; Miller \& Mumford, 1972); it is only when their devotees make far-ranging claims for the virtues of their diets that one may take exception. Vegetarian olympic champions are used to demonstrate the value of the diet, meat is blamed for causing aggression and stress, and it is claimed that because man in the Miocene period ate only plant foods his digestive tract is therefore unsuited to animal products. According to Graham ( 1883 ) fruits, nuts, farinaceous seeds and roots, with perhaps some milk and maybe honey, 'in all rational probability' constituted the food of the first family and the first generations of mankind.

Whole foods. As with vegetarianism there is a great deal to be said in favour of eating wholegrain cereals rather than highly milled products with less vitamins, minerals and proteins and very much less dietary fibre.

The value of roughage in the diet was certainly pointed out by health food supporters (among others) long before it attained its recent popularity with both the medical profession and the lay public. The current situation has been summarized in the Lancet (Lancet, r977) as follows: 'about five years ago dietary fibre burst into the consciousness of the medical world, having smouldered at the back of some minds for decades'. Similarly in the British Medical Fournal (British Medical Journal, 1977): 'enthusiasm for fibre is sweeping the world (the new craze is one of the oldest inventions of nature): However, foods like molasses and brown sugar are included in this group with no justification since these are products that have been extracted and refined to at least $95 \%$ of the extent of white sugar. Moreover, if the term whole foods is taken to its logical conclusion then potatoes, oranges and bananas should be consumed with their skins. Indeed, orange peel is a source of citrin, once termed vitamin $\mathrm{P}$, and dried citrus peel has been sold in health food shops as a source of 'bioflavonoids', which of course it is, but without any known benefit to man.

Organically-grown foods. It is argued that the state of health of man is, at least in part, related through animal and plant products to the state of the soil in which the food originated. Inorganic salts, the weight of tractors and oil dripped from them are considered highly detrimental to the soil while, on the contrary, the use of plant or animal manure is thought to produce nutritionally superior crops.

All such nutritional claims are completely devoid of evidence (White, 1974) and are based on belief in the mythology of organic farming. Certainly organic material is an extremely valuable aid to soil texture but has never been shown to be superior as a source of nutrients to natural, inorganic fertilizers. Inadequate supplies of nutrients for plants result in reduced yield but not in change in nutritional quality. It is, indeed, difficult to carry out a controlled comparison since the types of plants that grow best on organically manured ground, rich in humus, are often different from those types that succeed best with inorganic fertilizers. 
The high cost of organically produced foods can be partly explained by the low productivity and the cost of collecting from a number of small farms. The nutritionist sometimes concludes his discussion of this topic by stating that while there is no nutritional advantage in paying the extra cost, the individual may decide that the taste of the organically produced food is worth the price. There is, however, no objective evidence that the taste of these foods can be distinguished from that of 'ordinary foods'.

While there is no reason to doubt the sincerity of 'organically' produced products in Great Britain it has been stated that many such products are wrongly and dishonestly labelled in the United States (Kamil, 1972).

Avoidance of chemicals. All of us share a common fear of the toxic effects of residues from pesticides, herbicides and fungicides in our food. Farmers have often been guilty of overdosing, and extremely unpleasant chemicals were in use until recently. The health food addict has no monopoly of fear of toxic residues nor of the desire to develop alternative methods of pest control but with adequate monitoring and regulation of the use of chemicals it should be possible, and has indeed proved possible, to keep residues down to harmless levels.

The over-riding problem is that it is not possible to produce food in the amounts needed without these chemical aids. Man 'interfered' with nature a very long time ago and now without the chemical factory the world would starve.

Natural foods. Much stronger than the preference for organically-grown, unsprayed foods is that for 'natural' unprocessed foods. There is continuing suspicion about 'what they are doing to our food' and changes considered progress by food scientists and technologists, ranging from freeze-drying to instantization, are often regarded as depriving the individual of his right to nature's bounty.

'Natural' foods have considerable appeal at a time of personal rebellion against regimentation, mass production and the common battles with an impersonal bureaucracy. The term 'natural' is being exploited by the advertisers who claim, for example, that butter is natural while their competitors claim that margarine is made from natural ingredients.

The consumer may well feel exploited but is also exploited by health food claims exemplified by the following (Walters, 1971): 'While engaged on a haematological investigation in a maternity hospital I observed that in a series of 2000 patients many women who had subsisted mainly on forced-fertilized and variously processed or frozen foods showed an increased incidence of anaemia during pregnancy ... diminished blood serum iron, vitamin $B_{12}$ and folic acid levels'. No evidence is supplied about the type of diet, the numbers of 'many' women compared with the others, nor what the 'increased incidence' is compared with.

At the same time there is considerable appeal to nostalgia, anything new is suspect and consequently anything older is preferable. 'If it was good enough years and years ago it must be good enough now' (LBC, 1978).

Perhaps the sale of 'hand-potted marmalade made in copper vessels' epitomizes this attitude. The designation hand-potted shows the product to be more natural, more like home-made and therefore superior to a product poured through a tap 
from a machine. Copper, of course, was the standard material for factory vessels before the invention of stainless steel and so supplies the nostalgia of the good old days, ignoring, of course, the fact that all the vitamin $C$ is completely destroyed.

It is, of course, not popular knowledge that 'natural' foods like rhubarb, the brassicas and legumes contain toxins, and that even dietary essentials such as vitamin C, salt and water are lethal if consumed in large quantities. 'Natural' foods are considered good, anything processed is no longer natural and consequently is bad.

Certainly the flavour of fresh food ('garden-fresh' must often be distinguished from 'market-fresh') is far superior to any other version of the food and nutrients such as vitamin $\mathrm{C}$ are at their peak, but it is quite impossible to feed urban concentrations solely on fresh foods. What processing does achieve is to retain the greater part of the nutrients for periods of months and years. Frozen foods can even be superior in vitamin $\mathrm{C}$ content (and possibly other nutrients) to marketfresh foods if they were properly processed at their nutritional peak (Bender, 1978). Even canned foods can be richer in some nutrients than the stale unprocessed equivalent.

Magic foods. The group most open to condemnation, second perhaps only to the pills and potions, is that of specific foods with amazing health giving properties, foods such as buckwheat, yogurt, molasses, seaweed, garlic and honey. The foods promoted appear to have one property in common, namely, they are little eaten in the community in question (this is taken as a reason for the ills of that particular community) although they may be common foods in other communities. For example, buckwheat is a relatively rare food in Great Britain but it is the food of peasants in central Europe and the middle class in northern America. It is consequently promoted as a special food. Yogurt once enjoyed a similar reputation as a food that permitted Bulgarian peasants to live to the somewhat precise age of 107, until it became commonplace in this country. The emphasis now shifts to 'live' yogurt, since this is not the common article of commerce and its content of bacteria foreign to the human intestine is regarded as conferring special benefits.

Honey, possibly because of its unusual source and high price, has enjoyed a reputation for centuries, quite undeserved since it is little more than glucose and fructose. Of course 'little more' could include an accessory food factor of unknown potency. While the humility of the scientist must always force him to admit the possibility of such unidentified factors (just as cod liver oil was an accepted and valuable remedy long before its content of vitamins was discovered) it strains the imagination when honey is claimed to prolong life, promote the growth of extraordinarily beautiful hair and allow divers to reach hitherto unattainable depths in the sea. Bees' royal jelly and pollen are sold at exorbitant prices with claims in the range of science fiction and there is always a successful athlete or healthy geriatric to support such claims.

H. G. Wells showed many years ago (Wells, rgog) how it is possible to market pure water with extravagant claims, such as, indeed, were the stock-in-trade of the medicine man of the last century. Ginseng in particular is currently popular in 
many western countries as an exilir of life. According to the Chinese Materia Medica (Stuart, IgII) it establishes the soul and according to modern sales literature, supported by recent research in Russia (sic), it brings bodily functions back to normal (Appleby, undated). The fact that Ginseng has been famous as a medicinal plant for 5000 years makes it attractive but it appears that research into its properties began only in the 1950 a at the Institute of Biologically Active Substances in Vladivostock. Evidence given by Swedish workers to the International Ginseng Symposium held in Korea in the 1970 (Appleby, undated) revealed that Ginseng improved the mental processes as well as having anti-stress properties. The new improved variety, eleutherococcus senticosus Maximowics has been shown to contain one of 'a new and very important group of rare adaptogen substances which include Ginseng, dibazol and vitamin B $B_{12}$ ' (Appleby, undated) and so may supersede the dominance of the markets established by the Korean Monopoly Office.

The claims for cider vinegar rival those for Ginseng. It is said to eliminate the fat in the body instead of allowing it to be stored. The leaflet adds, 'it's as well, of course, to avoid foods you know to be particularly weight making. Apart from that there's no need to diet'. (Martlet, undated).

Pills and potions. One of the problems of discussing health foods as a single entity is that some but not all health food supporters include in their diets a wide variety of pills and potions. Some believe that it is impossible to obtain all the required nutrients from 'modern' foods and therefore take a variety of multiple vitamins, mineral salt and herbal tablets.

While some of the literature warns the consumer to beware of chemically manufactured vitamins because 'they lack the intrinsic factor' synthetic vitamin preparations are sold side by side with those extracted from food sources. These, of course, are highly refined but regarded as natural.

Another approach is that of advocating a natural balance of $B$ vitamins by taking yeast extract or wheat germ or other rich sources of B vitamins, assuming that the vitamins in that food are present in the same ratio as required by man. The commercial instinct clearly overcomes the moral approach when one finds single $B$ vitamins offered for sale on the adjacent shelf.

One of the more pernicious of the pills is the treatment of disease by simple inorganic salts because their manifold claims to cures of quite severe symptoms might well prevent or delay taking medical advice.

The dishonesty is revealed by the names used for them. Few people would spend much on tablets of common salt even if labelled sodium chloride, but this is disguised under the ancient name of natrium muriate. Similarly sand is called silicon oxide and plaster of Paris, much cheaper at the hardware stores, sells in health food stores under the name of calcium sulphate. A book for self diagnosis and treatment is included.

Herbal remedies appear to be based on the writings of Culpeper some 400 years ago and so fulfill the requirements of those revolting against modern regimentation. Over the centuries almost every wild plant has been claimed to cure 
an infinite variety of disorders. There may be substance in some of these claims since so many of our drugs are extracted from plant materials but there are two obvious problems. The concentration of drugs in the plants is much lower than required for therapeutic purposes, hence the complex extraction and concentration processes of the pharmaceutical industry and it is not necessarily beneficial or even prophylactic to consume drugs as foods.

Medical problems have arisen from herbal remedies 'bought from a health food shop'. One patient suffered from blurred vision, dry mouth, hallucinations and retention of urine after drinking burdock root tea bought from a health food shop. It was pointed out that the burdocks are widely used for 'nutritional and medical purposes' and contain large amounts of an atropine-like alkaloid, but 'surprisingly' there have been no previous reports of toxic effects (British Medical fournal, 1978).

A new problem appears to have arisen from the sale as a health food of salads including soaked, raw beans and ten cases of food poisoning attributed to haemagglutinins have been reported (Public Health Laboratories, 1976).

All these problems exist on a much greater scale in the United States. Young (1970) describes the sales of a thyroid extract which 'continued for a quarter of a century poisoning countless obese young women'.

Many of the products, such as sauerkraut juice from cabbage-grown-onorganically-manured-ground and a well-known mixture of malt, orange juice and extract from yeast grown on ' 93 different herbs', originate in Switzerland and graduate via Germany to the rest of Europe. There always appear to be Swiss Clinics able to provide testimonials, even to the man who lived, so it was claimed, for two months without food or liquid of any kind (Bender, interview on Independent Television).

There appears to be no rationale behind mixtures of 'nutrients' such as Ginseng $\mathrm{G}$, vitamin $\mathrm{E}$ and $\mathrm{B}_{6}$; perhaps only the opportunity of an advertising logo, ZEST, behind such a mixture as zinc, vitamin E, Ginseng and Tunera (damiana aphrodisaica), labelled with the health warning 'for adults only'.

\section{Honesty and prices}

According to the Which? report (Which?, 1978) some products do not live up to their claims. Nearly half of the 20 samples of dried fruit examined had been treated with sulphur dioxide, although most, contrary to law, did not state this on the label. Some 'natural' vitamin mixtures included ergocalciferol and other synthetic vitamins. Health food addicts are the main supporters of highly processed soy products, extracted, processed, coloured, flavoured and enriched with vitamins and iron-just as those other despised products.

According to the public analyst many of the descriptions are misleading and breaking the law (McLachlan, I972). In the United States, where health foods are far more widely advertised and sold than in the UK, there appears to be considerable suspicion of the honesty of the labelling (Kamil, 1972).

The Which? report (Which?, 1978) stated that the average price for the same 
brand of flour and cereals was about $5 \%$ less in ordinary supermarkets than in health food shops while mineral waters, dates, some treacles and sugar were about $15-20 \%$ less.

Of twelve foods of different brands but "likely to be of the same quality and nutritional value', the survey showed that wholefood shops and supermarkets sold own brands cheapest; unbranded foods from health food shops were more expensive; and branded foods from health food shops were on average, $50 \%$ dearer than wholefood shop prices (Table I).

Table I. Comparison of prices in health food shops and wholefood warehouses expressed as percentage change in 'ordinary' prices

Dried apricots
Lentils
Split peas
Clover honey
Brown rice
Walnuts
Wholemeal flour

Health food shop

$$
\begin{array}{r}
+62 \\
+26 \\
+13 \\
+120 \\
+23 \\
+41 \\
+25
\end{array}
$$

Wholefood warehouse

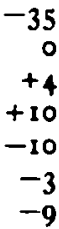

A survey carried out by Diane McCrea (unpublished results) in 1977 revealed the price differentials shown in Table 2. It will be noted that six branded foods cost $10-28 \%$ more for the same product in the health food shop.

Table 2. Differences between 'ordinary' and health food prices expressed as percentage of 'ordinary' prices (Relative prices fuly 1977)

\section{Meats}

Lamb cutlets

Ox liver

Minced beef

Sausages

Braising steak

Chuck steak

Rump steak

Vegetables

Broad beans

Cabbage

Cucumber

Lemons

Lettuce

Mushrooms

Onions

Peas

Potatoes

Runner Beans

Tomatoes
Dry Goods

$$
\begin{array}{r}
+27 \\
+21 \\
+25 \\
+110 \\
+37 \\
+10 \\
+20
\end{array}
$$

$+60$

$+66$

$+32$

$+100$

$+60$

$+37$

$+27$

$+50$

$+33$

$+42$

$+33$

Sugar:

Honey:

Flour:
Demerara +52

Muscovado +40

Black treacle* +15

Australian $\quad+47$

Mexican +55

Pure, thick ${ }^{*}+28$

Orange blossom +51

$100 \%$ organically grown $\quad+7$

$100 \%$ wholewheat ${ }^{\circ}+$ ro

$81 \%$ farmhouse +II

Bemax * +15

Bran +25

Eggs, free range +28

Cottage cheese +17

Butter +23

Salt, sea salt $v$. ordinary $\quad+225$

-Same brand. 
The biggest difference, I I0\% extra for sausages, is probably not comparing like with like but the other meat products must be very similar in both types of shops and cost 10 to $37 \%$ more in health food shops.

Fruit and vegetables are always far more expensive and this may be partly due to the relatively low yields obtained without inorganic fertilizers and chemical aids, the problems of collecting from a number of small farms, as well as the more obvious reason that the shops are mulcting the faithful.

Since lemons are not grown in this country it is questionable whether they are worth twice the price at the health food shop: they are claimed to be organically grown and free from chemical aids, but it is very doubtful whether such claims could be substantiated in any imported food. An example of exorbitant pricing is that of clover honey costing $120 \%$ more than the ordinary equivalent with no evidence of whether or not the bees collected their nectar from untouched natural flowers.

More recent figures, 1978 , show that grapefruit marmalade sells in one health food shop at $23 \mathrm{p}$ for $8 \mathrm{oz}$ and $49 \mathrm{p}$ per $\mathrm{lb}$, presumably under the influence of spiritual reawakening the purchaser is not expected to notice that twice $23 \mathrm{p}$ is not 49p. The nearby supermarket sells marmalade at $23 \mathrm{p}$ per $\mathrm{lb}$. It is suprising to find that these special marmalades include, according to the label, added pectin, from which one must conclude that the product is heavily diluted with sugars. Apricot jam, free from added colours, is twice the price of a nationally advertised variety.

The same shop sells camomile tea and lime blossom tea at $35 \mathrm{p}$ for $2 \mathrm{oz}$, described as 'slightly sweetened'. The label shows that the first ingredient is sugar (unrefined of course) followed by lactose and finally by extract of lime blossom.

With regard for intrinsic value for money in products that are not available in ordinary stores, one London, Oxford Street, store sells kelp (ocean flora that grows to great heights) at $45 \mathrm{p}$ per oz, supplying $200 \mathrm{mg}$ calcium, $5 \mathrm{mg}$ iodine and $2.5 \mathrm{mg}$ iron/oz. Sea salt is sold at $35 \mathrm{p}$ for $500 \mathrm{~g}$ compared with supermarket prices of 8.7p; sesame sea salt works out at $154 \mathrm{p}$ for the same amount.

Skim milk powder costs $54 \mathrm{p}$ for $8 \mathrm{oz}$ with $28 \mathrm{p}$ for a nationally advertised brand.

\section{Conclusion}

Modern living is blamed, probably quite rightly, for many of our ills, but the way in which this is expressed is nonsensical. Every processed food is damned and the solution lies in whole natural foods. We are criticized as a community for treating drinking water with chlorine and so destroy our supply of vitamin E (Balfour \& Allen, 1973); sodium fluoride, which is added to water (sic) destroys precious enzymes; atmospheric pollution destroys the vitamin $\mathrm{C}$ complex. The remedy is to supplement the diet with mineral and vitamin supplements obtained from natural sources, presumably by some complex chemical process of extraction, recrystallization, solvent treatment or whatever form of refinement the chemist needs to employ. The reason for extracting them from natural sources is that they will then be balanced, chemically manufactured preparations can be illbalanced.

When we, as scientists, criticize the sale of health foods, we must be aware that 
we may be undermining the faith that is one of the reasons why such foods are bought. Is it fair, merely in the interests of scientific accuracy, to remove the faith of those willing to pay for it? On the other hand we have a clear duty as the only small section of the community that is aware of the facts, to inform the public and to draw attention to the excessive prices charged by the monopolists in that area.

Finally, the evidence for the value of health foods can be summarized by the start of a paragraph by Pearse (197I), 'In this anecdote there is incontrovertible evidence...'

\section{REFERENCES}

Appleby, J. H. (Undated). Sales leaflet, 'A new ginsengs?' (No publisher's imprint).

Balfour, M. \& Allen, J. (1973). The $A$ to $Z$ of Health Food Terms. Garnerstone Press: London. Bender, A. E. (1 978). Food Processing and Nutrition, Academic Press: London.

Br. med. F. (1977). Editorial ii, 418 .

Br. med. \%. (1978). ii, 576 .

Cruickshank, J. G. \& Williams, H. R. (1978). Br. med. J. ii, 739.

Ellis, F. R. \& Mumford, P. (1967). Proc. Nutr. Soc. 26, 205.

Graham, S. (1883). Lectures on the Science of Human Life, (First ed. 1839) Fowler and Wells: New York.

Higginbottom, M. C., Sweetman, L. \& Nyham, W. L. (1978). New Engl. F. Med. 299, 317.

James, P. (1978). Br. Med. F. i, 1345 .

Kamil, A. (1972). J. Nutr. Educ. 4, 92.

Lancet, (1977). Editorial ii, 337 .

London Broadcasting Company (1978). Spokesman for the Festival for Mind and Body: London Broadcasting Company.

McLachlan, T. (1972). Roy. Soc. Hlth. Joum. 92, 58.

Martlet (Undated). Advertising leaflet Cider Vinegar. Martlet Health Food Products: Sussex.

Miller, D. S. \& Mumford, P. (1972). Pl. Fds hum. Nutr. 2, 201.

Pearse, I. H. (1971). In fust Consequences, p. 72 [R. Waller, editor].

Public Health Laboratories. (1976). Br. med. $\mathcal{~}$. ii, 1268.

Rose, M. (1976). Lancet. ii, 68I.

Sanders, T. A. B., Ellis, F. R. \& Dickerson, J. W. T. (1978). Br. J. Nutr. 40, 9.

Stuart, G. A. (191 I). Chinese Materia Medica. Shanghai.

Walters, A. H. (I971). In fust Consequences, p. 172 [R. C. Waller, editor].

Wells, H. G. (1909). Tono-bungay. Macmillan.

Which? (1978). June pp. 319-324. Consumers' Association.

White, P. L. (1974). Nutr. Rev. Supplement July Vol 32. I-73. p. 54

Young, J. H. (1970). Food Cultism and Nutrition Quackery, p. 9. Almqvist and Wiksells: Uppsala. 